\title{
A pintura do poema "Castigo pro comboio malandro", de António Jacinto: domínio musical e da linguagem como forma de encenar a construção da nacionalidade
}

\author{
Emanuela Francisca Ferreira Silva*
}

\begin{abstract}
Resumo
António Jacinto e outros escritores angolanos criaram em Luanda, em 1948, o Movimento dos Novos Intelectuais de Angola - MNIA -, que teve como lema o brado "Vamos descobrir Angola". O MNIA defendia o fortalecimento das relações entre literatura e sociedade e o debruçar-se sobre Angola e sua cultura para romper com a tradição cultural imposta pelo colonialismo. O poema "Castigo pro comboio malandro", de António Jacinto, seguindo os objetivos do movimento, além de se apresentar em forma escrita, foi declamado e musicado para melhor alcançar os habitantes das zonas rurais. Essa diversidade de suportes será considerada neste trabalho, que analisará o poema e a interpretação musical feita por Fausto Bordalo Dias no disco A preto e branco, tentando perceber como a pintura que a música faz no texto do poema consegue, através de analogias, estruturar nossa compreensão de maneira mais abrangente em relação a ambos os domínios: o da linguagem escrita e o musical.

Palavras-chave: Movimento Vamos descobrir Angola. Poema Castigo pro comboio Malandro. Linguagem escrita e musical. Analogias.
\end{abstract}

\section{"Vamos descobrir Angola": um brado em busca de liberdade}

Em meio a duas realidades distintas, a sociedade colonial e a sociedade africana, muitos escritores africanos, ainda no período colonial, faziam de sua literatura uma forma de resistência, expressão da tensão reinante nos espaços de dominação portuguesa e de legitimação da identidade cultural que o texto ajudava a construir.

A literatura angolana também conviveu com essa dupla realidade até sua independência, em 1975. As críticas à colonização portuguesa e a procura por uma Angola mais próxima de suas expressões mais genuínas foram importantes

*Pontifícia Universidade Católica de Minas Gerais - PUC Minas. 
para a constituição do projeto do Movimento dos Novos Intelectuais de Angola, fundado em 1948, que ficou conhecido pelo brado que o configura: "Vamos Descobrir Angola". Este brado foi lançado em Luanda por um grupo de estudantes e intelectuais angolanos que tinham como objetivo romper com o tradicionalismo cultural imposto pelo colonialismo. (FONSECA; MOREIRA, 2003).

Para tanto, era preciso adentrar pela cultura angolana, enfocando as aspirações e os problemas do povo angolano numa relação intrínseca entre literatura e sociedade. Tem-se assim a defesa de que a literatura se tornasse um espaço propício à construção de uma Angola imaginada, cuja identidade delineava-se pela recorrência a aspectos culturais do país e pela intenção de resistência que o texto abrigaria. Ana Lúcia Lopes de Sá, procurando explicar a relação da literatura angolana do período colonial com a construção do projeto de nação, afirma: "O texto literário tem uma natureza simbólica. A literatura é um repositório de cultura e uma forma de representação da identidade. Identidade e literatura conjugam-se, deste modo, enquanto processos e estratégias simbólicas e culturais". (LOPES DE SÁ, 2011). A literatura produzida pelos escritores do MNIA procurou assim refletir o cotidiano africano e encenar particularidades do povo, valorizando as suas línguas, costumes e crenças.

Trabalhando a literatura por esse viés, o poeta Viriato da Cruz é o primeiro a lançar o brado "Vamos descobrir Angola", em 1948, juntamente com outros escritores da época. Este brado procurou retomar o espírito destemido e questionador dos escritores e jornalistas angolanos do final do século XIX e do início do século XX, que, como Cordeiro da Matta, também ansiaram por construir uma identidade angolana valendo-se dos caminhos propostos pela literatura.

O brado "Vamos descobrir Angola" irá se mostrar na produção literária do grupo que, segundo Fonseca e Moreira, privilegiará a poesia, porque:

Através da poesia, descobre-se Angola, conhecem-se as suas origens, as suas tradições e os seus mitos. A poesia adquire uma intencionalidade pedagógica e didática: com ela tenta-se recriar África e Angola, os valores ancestrais do homem a descobrir-se como individualidade. Essa poesia põe em prática a reposição da tradição oral, onde as próprias línguas nacionais ocupam um espaço importante. É, numa palavra a poesia da 'angolanidade'. (FONSECA; MOREIRA, 2003 - destaques nossos)

A poesia é um caminho proposto pelos escritores que criaram o Movimento dos Novos Intelectuais de Angola. Com esse gênero, os escritores assumiam 
a preocupação de que os jovens precisavam conhecer Angola, através de um trabalho organizado que passava, inclusive, pelo combate ao respeito exagerado e não crítico aos valores culturais do Ocidente. Para alcançar os seus objetivos, os escritores se envolviam com uma série de atividades culturais como campanha de alfabetização, fundação de escolas e bibliotecas, edição de trabalhos, criação de concursos literários, lançamento de revistas, entre outros planos.

A palavra escrita só chegava, à época, a uma parte insignificante da população e somente àqueles que dela podiam se apropriar. Assim, o ponto principal deste projeto era a alfabetização da população para que ela pudesse ter acesso aos pensamentos e inquietações que assolavam os novos intelectuais angolanos.

A polícia salazarista percebeu o perigo que a literatura representava para a segurança do processo colonizatório e, por isso, interditou a publicação da revista Mensagem, logo após a publicação do segundo exemplar, em edição dupla. Entre os temas da revista estavam reinvindicações literárias e culturais que apontavam para a conscientização da exploração colonial e independência de Angola. Teresa Salgado, ressalta a tentativa de alguns dos escritores de, proibida a revista Mensagem, procurarem outros meios para divulgar os seus textos:

Desaparecida Mensagem, os escritores angolanos buscam outros meios de divulgar suas produções e encontram na revista Cultura II uma continuação do espírito desbravador de Mensagem. Tendo desempenhado, entre 1945 e 1954, um papel cultural apenas superficial, Cultura recomeçou a ser publicada em 1957, como Cultura II, adotando um novo perfil: divulga poemas, textos e ensaios protestatários e conscientizadores da situação sócio política. Ao mesmo tempo em que se abre mais ao que está acontecendo no mundo, a revista discute, cada vez mais intensamente, temas voltados para as línguas e as culturas locais. (SALGADO, 2011)

Angolanizar a literatura é descolonizá-la através da palavra escrita. E, nesse sentido, o poema "Castigo pro comboio malandro", de António Jacinto, faz parte desse propósito que defendia a cultura angolana. Valendo-se de imagens associadas ao trem, o poema enfoca uma temática social que permite que o meio de transporte seja visto como crítica severa à colônia e a seus métodos de repressão.

Este poema foi declamado para chegar ao povo e, posteriormente, musicalizado por Fausto Bordalo em 1988 e gravado no álbum A preto e branco. Pintar o texto literário com harmonias, melodias e ritmos parece ser um 
instrumento importante para que os ideais do Movimento dos Novos Intelectuais de Angola pudessem atingir de maneira direta a população angolana. O poema musicado é acessível a mais pessoas porque assume estratégias da oralidade com as quais canta o processo e a luta pela descolonização literária. Musicar um poema é maneira nova de trazer para a oralidade os sonhos e pensamentos dos novos intelectuais angolanos.

Partindo dessa premissa, apresento uma análise do poema "Castigo pro Comboio Malandro", do escritor António Jacinto, enfocando a junção da letra à música - pintura do texto - como uma estética capaz de proporcionar um blend space, afirmando o compromisso da geração de 1950 de recuperar a tradição angolana e afirmar sua identidade.

É importante ressaltar que a produção poética da Geração de 50 pode ser caracterizada como um esforço em combinar poesia narrativa e ritmo sincopado, trazendo a estrutura musical do semba - dança africana - para se mesclar à linguagem na tentativa de levar aos leitores - ouvintes os ideais de liberdade e de identidade.

\section{Castigo pro comboio malandro: pintando o texto com música}

O movimento dos Novos Intelectuais de Angola tinha como tema principal a valorização da terra. Este tema podia se ligar ao desejo de retorno às origens ou, conforme se acentua no poema, ressaltar a exploração cruel da terra e de sues habitantes. O poema "Castigo pro comboio malandro", de António Jacinto, vai trabalhar nesta segunda perspectiva, trazendo para o leitor um comboio que, metaforicamente, se transforma durante todo o seu trajeto por caminhos angolanos.

No poema, a cena literária torna-se um lugar de discussão em que valores como justiça social e solidariedade não podem ser considerados secundários frente aos padrões estéticos. Na forma escrita do poema "Castigo pro comboio malandro", há uma tentativa de assumir, por meio de recursos que valorizam a sonoridade, o ritmo da música africana que se hibridiza aos versos, seja pela abolição das pausas intensas e pela mescla de línguas, portuguesa e kimbundo, seja pela repetição de palavras ou pelo uso intencional de onomatopeias que trazem para a mente do leitor-ouvinte o a imagem do trem como metáfora do processo colonizador.

A teoria da estética de Scruton (SCRTON apud ZBIKOWSKY, 2009) coloca o trabalho de arte no reino da intenção. Segundo Zbirowsky, Scruton argumenta que ouvir sons, como música, exige o domínio de conceitos vindos de outros 
domínios. Na versão musicada do poema de António Jacinto, as onomatopéias se mesclam ao ritmo sincopado e trazem para o leitor-ouvinte a ideia do trem em movimento. Uma ilusão em que transferimos conceitos de um domínio (movimento no espaço pelo comboio) para outro - a audição musical marcada pelas onomatopeias: "hii hii hii, muú muú muú, Te-quem-tem te-quem-tem tequem-tem". Esse processo omomatopaico irá se repetir durante todo o poema, acentuando a ideia de movimento do trem, cujos sons e apitos se misturam aos mugidos dos bois.

As onomatopeias como ué ué ué também são recursos que reproduzem, no poema, o movimento do trem. Sente-se o comboio percorrendo as distâncias, sempre se transformando aos olhos dos que sabem ler e ouvir. Ele finge ser apenas veículo de transporte, mas queima as casas e o milho da roças, transformando-se em perigoso inimigo que precisa ser enfrentado com a espingarda de quimbundo. Assim, a cada momento, as mesmas onomatopeias assumem uma diferente força expressiva.

O poema também explora outros recursos como a metáfora e a personificação para ressaltar as múltiplas transformações pelas quais o comboio passa. De meio de transporte para as "n'ganas bonitas/quitandeiras de lenço encarnado/ (que) levam cana no Luanda pra vender", a veículo que transporta bois e de gente que vai para o trabalho de contrato. Assim, as várias feições do comboio vão se mostrando quando os versos dizem: "aquele vagon de grades tem bois/ muú muú muú/tem outro/igual como este dos bois leva gente, muita gente como eu cheio de poeira/gente triste como os bois/gente que vai no contrato." Essas várias feições do trem aludem ao sistema de opressão, em que gente e boi são mercadoria para venda e, por isso, ocupam, como carga, vagões similares no comboio.

Pode-se perceber que o poema lida com imaginários ligados à ideia de gente pode ser considerada peça ou coisa. Por isso, no poema, as imagens acentuam que o comboio carrega carga como a dos bois, mas carrega também gente como carga, ambos, portanto, como mercadoria. Essas imagens mostram-se através de um importante trabalho com a linguagem que atinge vários níveis metafóricos que o ritmo, no poema e os recursos, na musica, ressaltam com intensidade.

Entretanto, se se faz a comparação entre boi e gente, os versos acentuam a diferença entre as duas mercadorias: "tem bois que morre no viaje/mas o preto não morre/ canta como é criança / Mulonde iá késsua uádibalé uádibalé uádibalé...”. A recorrência ao quimbundo intencionalmente recolhe o canto que 
acalma e que faz o angolano recobrar as suas forças. Ainda que considerado carga, como os bois, ele tem direito às lembranças da infância que lhe vêm através do canto. Com esse recurso, o poema reforça a diferença entre as duas cargas levadas pelo comboio e reafirma a resistência o contra a opressão. A viagem reitera a ordem da colonização, mas, ao mesmo tempo, afirma que resistir é não morrer para enfrentar essa forma de dominação enquanto se espera pela liberdade.

Ao se descrever o comboio como malandro, o poema acentua as metamorfoses pelas quais o trem passa, quando alude ao fogo "que sai no corpo dele vai no capim e queima/ vai nas casas dos pretos e queima". O comboio malandro assumindo várias imagens mostra-se como agente da repressão que passa por Angola destruindo tudo: as casas, o capim, o milho, referências à terra, tanto focada pelo movimento dos Novos Intelectuais Angolanos.

É interessante verificar que o eu-lírico se coloca no poema quando afirma: “já queimou o meu milho". O eu-lírico faz parte do povo que está sendo explorado e dominado. Por isso, metaforicamente o povo assume a semelhança entre a semelhança entre o povo e os bois, mas, ao mesmo tempo, mostra o povo diferente dos bois mansos e dóceis.

É com a mesma estratégia que se percebe uma reflexão no interior do poema sobre estratégias para vencer o inimigo: "Se na lavra do milho tem pacaças ou kiombos, ele e o povo angolano sabe como se defender usando a espingarda de quimbundo, metaforicamente significando arma e língua. O poema ressalta, com a imagem, a força da tradição oral e reforça o trabalho de linguagem que envolve as mesclas entre as línguas de origem banta e o idioma português. E a "espingarda de quimbundo" se mostra como a língua híbrida que assume a consciência crítica da época que aflora, no poema, como resistência ao dominador. Assim, quando se diz: "Tiro a espingarda de kimbundo" a imagem desloca-se da referencialidade para reforçar a força da língua nacional como luta contra os "kiombos" que, metaforicamente destroem as lavras. Vêem-se os kiombos como o colonizador e a lavra como a terra, o colonizado. E, no final do poema essa estratégia assume uma outra feição, quando o eu-lírico diz: "Mas espera só quando esse comboio malandro descarrilar/ e os brancos chamar os pretos pra empurrar/eu vou mas não empurro/ nem com chicote / finjo só que faço força/ Aka! Você vai ver só o castigo/ vai dormir mesmo no meio do caminho".

Considere-se que o poema, ao ser transformado música, forma um terceiro espaço, denominado blend space. A linguagem sobre música é muitas vezes 
metafórica e, isto se verifica na harmonia que se coloca como analogia para os sentidos que se quer enfocar no poema. No final do poema, os versos indicados acima são expressos com a presença de um acorde menor que parece produzir um sentimento triste, melancólico, que, de repente, se transforma em força intensa que registra a expressividade do final do poema.

Segundo Scruton esse processo de escolha de harmonia sobre a letra é intencional. A possibilidade de superficialidade na expressão musical é quase zero, ela sempre tem intenção. Relativizar conceitos como melancólico para um acorde menor é metaforizar esse trecho da música como sendo uma passagem em que o autor dos acordes procura expressar os anos ruins pelos quais passou o povo de Angola.

O mesmo ocorre nos trechos que sugerem a alegria em que a dominante, seguida pela fundamental, incita ao leitor-ouvinte a perceber um movimento acelerado, como o de um trem em movimento, sempre indicado pela onomatopeia "te-quem-tem-te-quem-tem-te-quem-tem". Como afirma Scruton, citado em Zbikowsky, afirma que "a metáfora transferida, pega conceitos de um domínio (como o movimento no espaço, ou de objetos concretos) e é aplicado em outro - na essência das audições musicais". (SCRUTON apud ZBIKOWSKY, 2009).

O movimento do trem faz parte de um outro espaço que não é do domínio musical ou da linguagem. Isso ocorre devido também ao ritmo que sugere por analogia esse movimento. A música não movimenta, não há subidas ou descidas, ela é uma onda sonora que varia as vibrações.

As reflexões sobre a estética formuladas por Scruton colocam o trabalho da arte no reino da intenção. Scruton se vale do argumento de que

escutar vários sons como música (em oposição a ruídos desagradáveis) exigem interpretação através de conceitos vindos de outros domínios. (...) O descendente é uma ilusão: o cantor não desce o som e não há nada de científico que demonstre que o som desce. (SCRUTON apud ZBIKOWSKY, 2009).

Essa ilusão de subida e descida de som é um dos pontos importantes na estética de Scruton. A música proporciona sentido por analogia. Assim ao se ouvir o poema "Castigo pro comboio malandro" musicado, temos conceitos vindos de outros domínios - como o espaço em física- para afirmar as metáforas propostas pelo poeta. A hibridização entre os elementos musicais e a letra do poema traz para o ouvinte o blend space, isto é, um terceiro espaço 
em que os sentidos se unem para que o leitor ouvinte consiga pintar pelo som as metáforas que aparecem em ambos os domínios: musical e da linguagem.

A percepção da estrutura musical é indivisível da resposta física e emocional. A metáfora se faz nesta analogia em que a harmonia e o ritmo que são típicos do domínio musical - apesar de haver ritmo no domínio da linguagem - influenciam o ouvinte a compreender de outra maneira a poesia de António Jacinto, pois esta é reforçada pala experiência psíquico-emocional que a música possibilita.

Assim, quando Fausto Bordalo canta o poema "Castigo pro comboio malandro", ele hibridiza o domínio da linguagem e o da música. Este movimento gera o blend space, isto é, o terceiro espaço que traz para o leitor ouvinte uma imagem sensório-cognitiva muito mais abrangente sobre o processo de angolonizar a terra via literatura.

A pintura que a música faz no texto do poema, através de analogias, estrutura a compreensão do leitor-ouvinte de maneira muito mais abrangente. O blend space que se faz pela mesclagem dos dois domínios, o musical e o da linguagem, trabalha e reflete esteticamente os ideias do Movimento dos Novos Intelectuais Angolanos na defesa de um mesmo ideal, o de angolonizar a terra, isto é, fortalecer uma identidade angolana em todas as suas vertentes culturais: a literatura, a língua, o ritmo e a música. 


\begin{abstract}
Antonio Jacinto and other angolanos writer's from Luanda they create in 1948, the Movimento dos Novos Intelectuais de Angola with the motto "Vamos descobrir Angola". O MNIA advocated the strengthening of relations between literature and society, without its culture to break with cultural tradition imposed by colonialism. The poem "Castigo pro comboio malandro", following the movement's goals, as well as performing in written form, recited to music and to better reach the people in rural areas. This diversity of support will be considered in this work we analyze the poem and this musical interpretation made by Fausto Bordalo Days (1988) on the album "A Branco e Preto", trying to understand how the painting that music is the text of the poem can, trough analogies, structure our understanding more broadly in relation to both areas: written languag.e and music.
\end{abstract}

Keywords: Movimento Vamos Descobrir Angola. Poem Castigo pro comboio malandro. Written and musical languagem. Analoge.

Referências

FONSECA, Maria Nazareth; MOREIRA, Terezinha Taborda. Panorama das literaturas africanas de língua portuguesa. Disponível em $<$ http:// www. pucminas.br/publicações >. Acesso em 26 Ago. 2011.

LOPES, Francisco José. Alfândega da fé - resistir no Nordeste. Disponívelem: $<$ http://resistente.3e.com.pt/joomla/index.php?option=com_content\&vie $\underline{\mathrm{w}}=$ article\& $\mathrm{id}=39$ :antonio-jacinto-poeta-angolano\&catid=2:trabalhos-publicados> Acesso em 29 Ago. 2011.

LOPES DE SÁ, Ana Lúcia. A ruralidade na narrativa angolana do século XX: elemento de construção da nação. Tese de doutoramento em Sociologia apresentada à Universidade da Beira Interior. Disponível em: $<$ http://www. adelinotorres.com/teses/Ana $\% 20 \mathrm{~L} \%$ FAcia $\% 20 \mathrm{de} \% 20 \mathrm{~S} \% \mathrm{E} 1$ A $\% 20$ ruralidade\%20na\%20narrativa\%20angolana.pdf $>$. Acesso em 10 Set. 2011.

QUIMBANZE. Quitexe. Disponível em: http://quitexe-historia.blogs.sapo. pt/53042.html. Acesso em 29 Ago. 2011. 
SALGADO, Maria Teresa. A geração de 50 e a modernidade literária angolana. Disponível em $<$ http://www.revistasarara.com/int pente finoTexto01. html $>$. Acesso em 24 Ago. 2011.

SOUZA, Helder de. Car vice. Disponível em: http://cars-vice.blogspot. com/2009/07/historia-do-circuito-da-fortaleza.html $>$. Acesso em: 29 Ago. 2011.

UNIVERSITY OF FLORIDA DIGITAL COLLECTION. Subsídios para o estudo da economia de Angola nos últimos cem anos. Disponível em http://ufdc. ufl.edu/UF00080796/00001/23j > Acesso em 29 Ago. 2011.

ZBIKOWSKY, A. Music, language and multimodal metaphor. In.: FORCEVILLE, C. URIOS-APARIS, E. Multimodal metaphor. Editora Mouton de Grujter. Germany, 2009. 